BIOCHEMICAL AND BIOPHYSICAL RESEARCH COMMUNICATIONS (ISSN: 0006291X) (eISSN: 1090-2104) 460: (3) pp. 863-867. (2015)

doi:10.1016/j.bbrc.2015.03.123 


\title{
Inclusion excluded: chiroptical sensing of the external surface of sulfated cyclodextrins
}

\author{
Ferenc Zsila ${ }^{*}$ \\ Research Group of Chemical Biology, Institute of Organic Chemistry, \\ Research Centre for Natural Sciences, Hungarian Academy of Sciences, POB 289, \\ H-1519, Budapest, Hungary
}

Corresponding author: Ferenc Zsila

POB 289, H-1519, Budapest, Hungary

Email: zsila.ferenc@ttk.mta.hu 


\begin{abstract}
It is shown that the heparin antagonist bis-aminoquinoline derivative surfen interacts with sulfated cyclodextrins in a unique fashion. Analysis of the UV spectroscopic data revealed exceptionally strong association $\left(K_{\mathrm{a}} \sim 10^{7} \mathrm{M}^{-1}\right)$ of several surfen molecules to the external surface of the cyclodextrin hosts. H-bonded to the sulfate groups in 1:1 stoichiometry, the drug molecules form a chiral layer around the macrocycles. Due to the steric proximity, dipole-dipole coupling occurs between the adjacent aminoquinoline rings that accounts for the large UV hypochromism and the induced exciton couplet in the circular dichroism spectra.
\end{abstract}

Keywords: circular dichroism; exciton coupling; hypochromism; sulfated cyclodextrin; surfen

Abbreviations: CD, circular dichroism; CDX, cyclodextrin; DS, degree of substitution; s $\alpha \mathrm{CDX}$, sulfated $\alpha$-cyclodextrin; s $\beta C D X$, sulfated $\beta$-cyclodextrin; s $\gamma \mathrm{CDX}$, sulfated $\gamma$ cyclodextrin 


\section{Introduction}

Sulfated cyclodextrins (CDXs) are highly hydrophilic, effective chiral selectors for the separation of enantiomers of chemically diverse cationic and neutral drugs [1]. Attached to the hydroxyl sites of the macrocycle, sulfate moieties can form hydrogen and ionic bonds with guest compounds. Despite of the combination of polar and hydrophobic cavity interactions, inclusion complexes of sulfated CDXs are featured with low-stability $\left(K_{\mathrm{a}} \sim 10^{1}-10^{3} \mathrm{M}^{-1}\right)$ and low capacity [2-5].

In contrast to these data, the present contribution demonstrates the unique, very highaffinity association of several surfen molecules on the outer surface of sulfated $\alpha-, \beta$ - and $\gamma$-CDX (the average degree of substitution (DS) is 11,12 , and 14, respectively). Surfen is a bis-aminoquinoline derivative (Scheme 1) that can bind to proteins [6,7] as well as anionic, linear-chain polysaccharides (e.g., heparin, chondroitin sulfate, dermatan sulfate) modulating a number of functional glycosaminoglycan-protein interactions [8-10]. 


\section{Materials and methods}

\section{Materials}

Surfen (cat\# 362330, purity $\geq 98.00 \%$ ) was obtained from Calbiochem. $\alpha$-Cyclodextrin sulfate sodium salt (DS 11, Mw 2095), $\beta$-cyclodextrin sulfate sodium salt (DS 12, Mw 2360), $\gamma$-cyclodextrin sulfate sodium salt (DS 14, Mw 2730) and natural cyclodextrins $(\alpha, \beta, \gamma)$ were supplied by Cyclolab Ltd. (Budapest, Hungary).

Preparation of surfen and GAG/DNA solutions

Stock solution of surfen was prepared freshly before each measurement in spectroscopy grade DMSO. The volume of DMSO added into the buffer samples during the $\mathrm{CD} / \mathrm{UV}$ titrations never exceeded 2\% (v/v). Cyclodextrin samples were made in $50 \mathrm{mM}, \mathrm{pH} 7.4$ Tris- $\mathrm{HCl}$ buffer containing $100 \mathrm{mM}$ sodium chloride.

\section{Circular dichroism and UV absorption spectroscopic measurements}

All spectroscopic experiments were conducted in $50 \mathrm{mM}, \mathrm{pH} 7.4$ Tris- $\mathrm{HCl}$ buffer containing $100 \mathrm{mM}$ sodium chloride. CD and UV absorption spectra were recorded on a JASCO J-715 spectropolarimeter at $25 \pm 0.2^{\circ} \mathrm{C}$. Temperature control was provided by a Peltier thermostat equipped with magnetic stirring. $\mathrm{CD} / \mathrm{UV}$ titration experiments were performed in a rectangular quartz cell of $1 \mathrm{~cm}$ optical path length (Hellma, USA). Each spectrum represents the average of two scans obtained by collecting data at a scan speed of $200 \mathrm{~nm} / \mathrm{min}$. Absorption spectra were obtained by conversion of the high voltage (HT) values of the photomultiplier tube of the $\mathrm{CD}$ equipment into absorbance units. $\mathrm{CD}$ and 
UV curves of surfen-CDX and CDX-surfen mixtures were corrected by blank buffer or buffer solutions of CDXs, respectively. JASCO CD spectropolarimeters record CD data as ellipticity (' $\Theta$ ') in units of millidegrees (mdeg).

\section{Calculation of the CDX binding parameters of surfen}

The surfen-CDX binding interaction can be quantified by the association constant $\left(K_{a}\right)$ :

$$
\mathrm{S}+\mathrm{CDX}=\mathrm{SCDX} ; \quad K_{a}=\frac{[S C D X]}{[S][C D X]}
$$

It is evident that

$$
\begin{gathered}
{[\mathrm{S}]=c_{\mathrm{S}}-[\mathrm{SCDX}]} \\
\text { and } \\
{[\mathrm{CDX}]=c_{\mathrm{cdx}}-[\mathrm{SCDX}]}
\end{gathered}
$$

where $c_{s}$ and $c_{c d x}$ mean the total molar concentrations of surfen and CDX, respectively. Since the formation of surfen-CDX complexes is responsible for the UV hypochromism (see Fig. 2), it can be written that

$$
\varepsilon_{0}-\varepsilon=k[\mathrm{SCDX}]
$$

Where $\varepsilon_{0}$ is the molar absorption coefficient $\left(\mathrm{M}^{-1} \mathrm{~cm}^{-1}\right)$ of the main UV peak of surfen measured in CDX-free buffer solution, $\varepsilon$ is the molar absorption coefficient of the same peak measured after addition of increasing amounts of CDXs into the sampe solution and $k$ is a constant. Using equations $1-4$, we obtain

$$
\left(\varepsilon_{0}-\varepsilon\right)=\frac{k}{2}\left(c_{s}+c_{c d x}+K_{a}^{-1}-\sqrt{\left(c_{s}+c_{c d x}+K_{a}^{-1}\right)^{2}-4 c_{s} c_{c d x}}\right)
$$

where $K_{\mathrm{a}}$ is the surfen-CDX apparent averaged association constant. 
In order to calculate the value of $K_{a}$, non-linear regression analysis was applied using NLREG $^{\circledR}$ (statistical analysis program, version 3.4). Number of surfen molecules bound per a CDX host $(n)$ was estimated by adjusting the molar concentration of surfen $\left(c_{s}\right)$ during the curve fitting procedure. For instance, the best curve fit on the UV titration data obtained with s $\alpha \mathrm{CDX}$ was achieved by entering $2.85 \mu \mathrm{M}$ of surfen concentration instead of the experimental value of $32 \mu \mathrm{M}$. The ratio of $32 / 2.85$ gives the average number of surfen molecules bound per a macrocycle (see Fig. 3). 


\section{Results and discussion}

Gradual addition of the optically inactive drug into the buffer solution of sulfated CDXs induced an intense, oppositely signed CD band pair (Fig. 1). This CD couplet consists of a longer-wavelength positive and a shorter-wavelength negative peak with a zero crossover point around $255-257 \mathrm{~nm}$, close to the $\lambda_{\max }$ of the main UV absorption band of surfen. These spectroscopic features are characteristic to strong excitonic interactions between the $\pi-\pi^{*}$ transitions of the aminoquinoline rings of surfen molecules. The induced ellipticity - drug concentration plot exhibit a steeper ascending and a second, rather flat phase (Fig. S1 in the Supplementary Data). The CD extrema reached a saturation above 10:1 surfen:CDX molar ratio.

In comparison with the UV profile of free surfen molecules, the blue shifted $(\sim 8 \mathrm{~nm})$ absorption peak displayed a significant hypochromism in the presence of sulfated CDXs (Fig. 1). The hypochromism is more prominent and can be better studied by a reverse titration adding sulfated CDXs to a constant amount of surfen. Each CDX produced a large, at least $50 \%$ reduction in the $\varepsilon_{\max }$ value (Fig. 2). In contrast to the CD titration data, the absorption changes were more uniform and thus could be used to estimate the apparent averaged host-guest affinity constants. Non-linear regression analysis of the molar absorption coefficients measured at increasing sulfated CDX/surfen ratios indicated exceptionally strong surfen-sCDX association (Fig. 3). This tight binding interaction $\left(K_{\mathrm{a}} \sim 10^{7} \mathrm{M}^{-1}\right)$ enables the chiroptical detection of sulfated CDXs at a concentration as low as $10^{-8} \mathrm{M}$ (Fig. S2 in the Supplementary Data). 
In the case of $s \gamma \mathrm{CDX}$, the substantial deviation of the data set in the plateau phase of the titration prevented the calculation of the stability constant. However, the overall similarity of the UV titration profiles suggests a $K_{\mathrm{a}}$ value of the same order of magnitude for s $\gamma \mathrm{CDX}$, too (Fig. 3).

It was found that the best non-linear fit for the UV data occurs at 11:1 surfen-s $\alpha \mathrm{CDX}$ and 12:1 surfen-s $\beta C D X$ stoichiometry that correlates well with the average DS values of these host compounds. This suggests that each sulfate group binds a single surfen molecule on the outer surface of CDXs. In analogy with the stacked base pairs of DNA, the proximity of the sulfate substituents may favour $\pi-\pi$ stacking of the surfen molecules bound to them producing a large hypochromism in the UV spectrum. Due to the asymmetric spatial disposition of the sulfate groups, the intermolecularly stacked aminoquinoline rings form a supramolecular, chiral layer around the macrocycle resulting in strong exciton $\mathrm{CD}$ splitting of intermolecular origin. Application of the exciton coupling theory [11,12] predicts that the observed positive-negative CD feature (Fig. 1) correlates with the right-handed ( $P$-helical) orientation of long axes of adjacent aminoquinoline moieties (linear dichroism measurements showed that in the parent 4aminoquinoline the electronic transition moment of the main UV band centered around $221 \mathrm{~nm}$ is oriented along the long axis of the molecule [13]).

Surfen can attach to the sulfate groups through ionic and H-bonding. The protonated basic ring nitrogens $\left(\mathrm{p} K_{\mathrm{a}} 9.17\right.$ [14]) may be involved in electrostatic interactions while the $-\mathrm{NH}_{2}$ substituents act as $\mathrm{H}$-donors. Noticeably, the replacement of the $-\mathrm{NH}_{2}$ groups with $-\mathrm{H},-\mathrm{OH}$ or $-\mathrm{OMe}$ substituents completely abolishes the heparan sulfate binding of surfen $[15,16]$. In addition, electrostatic complexes of basic organic compounds formed 
with sulfated glycosaminoglycans are highly sensitive to the ionic strength of the solution and dissociate at physiological salt concentration $[17,18]$. In contrast to this, surfen does bind to sulfated CDXs in the presence of $0.1 \mathrm{M}$ sodium chloride and increse of the $\mathrm{Na}^{+}$ concentration up until $1.25 \mathrm{M}$ caused only a small fluctuation of the $\varepsilon_{\max }$ value but did not cancel the UV hypochromism, the spectroscopic sign of CDX association of the drug molecules (Fig. S3 in the Supplementary Data). Interestingly, crystallographic studies showed that surfen can adopt a crescent-shaped conformation [6] where the amino groups face toward the same side occupying a favourable steric position to establish intermolecular H-bonds with the same sulfate substituent (Scheme 1). Concomittantly, the charged edge of the molecule points toward the bulk aqueous phase. This possible CDX binding mode of surfen is consistent with the 1:1 drug:sulfate stoichiometry (Fig. 3).

By contrast to the sulfated CDXs, native CDXs were unable to induce any ellipticity signal in the CD spectrum of surfen (data not shown). The main UV peak, however, exhibited a moderate ( 10\%) hypochromism (Fig. S4 in the Supplementary Data). Analyis of the $\varepsilon_{\max }$ values indicated a much weaker association $\left(K_{\mathrm{a}} \sim 10^{5} \mathrm{M}^{-1}\right)$ of 4-7 surfen molecules per a CDX host (Fig. S4 in the Supplementary Data). These results imply that presumably via the hydroxyl groups, surfen can bind to the external surface of natural CDXs, too. The small hypochromism, however, suggests a substantially larger intermolecular spacing between the guest molecules, the accomodation of which occurs in a non-chiral fashion.

In conclusion, the results described herein show that the hydrophilic external surface of sulfated CDXs may serve as an asymmetric template enabling a very strong, chiral 
supramolecular association of guest molecules. Dense packing of surfen molecules $\mathrm{H}$ bonded to the sulfate groups enables dipole-dipole coupling between the adjacent aminoquinoline rings giving rise to intense exciton $\mathrm{CD}$ splitting and large UV hypochromism. High-affinity/high drug loading ability of the sulfated CDX surface significantly improves the complexation efficiency and drug delivery potential that are limited for the conventional inclusion complexes. These data help to better understand the molecular recognition properties of sulfated cyclodextrins with a potential to extend further their applications. 


\section{Appendix A. Supplementary data}

Supplementary data associated with this article (additional CD and absorption spectra) can be found in the online version, at http://dx.doi.org.

\section{Acknowledgements}

Financial support of the 'Lendület' Program of the Hungarian Academy of Sciences (LP2013-55/2013) is acknowledged. 


\section{References}

[1] C.E. Evans, A.M. Stalcup, Comprehensive strategy for chiral separations using sulfated cyclodextrins in capillary electrophoresis, Chirality 15 (2003) 709-723.

[2] L. Escuder-Gilabert, Y. Martin-Biosca, M.J. Medina-Hernandez, S. Sagrado, Cyclodextrins in capillary electrophoresis: recent developments and new trends, J. Chromatogr. A 1357 (2014) 2-23.

[3] M.A. Rodriguez, Y. Liu, R. McCulla, W.S. Jenks, D.W. Armstrong, Enantioseparation of chiral sulfoxides and sulfinate esters by capillary electrophoresis, Electrophoresis 23 (2002) 1561-1570.

[4] S.R. Gratz, A.M. Stalcup, Enantiomeric separations of terbutaline by CE with a sulfated beta-cyclodextrin chiral selector: a quantitative binding study, Anal. Chem. 70 (1998) $5166-5171$.

[5] I. Fejős, A. Kazsoki, T. Sohajda, E. Márványos, B. Volk, L. Szente, S. Béni, Interactions of non-charged tadalafil stereoisomers with cyclodextrins: capillary electrophoresis and nuclear magnetic resonance studies, J. Chromatogr. A 1363 (2014) 348-355.

[6] R.G. Panchal, A.R. Hermone, T.L. Nguyen, T.Y. Wong, R. Schwarzenbacher, J. Schmidt, D. Lane, C. McGrath, B.E. Turk, J. Burnett, M.J. Aman, S. Little, E.A. Sausville, D.W. Zaharevitz, L.C. Cantley, R.C. Liddington, R. Gussio, S. Bavari, Identification of small molecule inhibitors of anthrax lethal factor, Nat. Struct. Mol. Biol. 11 (2004) $67-72$.

[7] T.J. Lanza, P.L. Durette, T. Rollins, S. Siciliano, D.N. Cianciarulo, S.V. Kobayashi, C.G. Caldwell, M.S. Springer, W.K. Hagmann, Substituted 4,6-diaminoquinolines as inhibitors of C5a receptor binding, J. Med. Chem. 35 (1992) 252-258.

[8] M. Schuksz, M.M. Fuster, J.R. Brown, B.E. Crawford, D.P. Ditto, R. Lawrence, C.A. Glass, L. Wang, Y. Tor, J.D. Esko, Surfen, a small molecule antagonist of heparan sulfate, Proc. Natl. Acad. Sci. USA 105 (2008) 13075-13080. 
[9] D. Xu, M.M. Fuster, R. Lawrence, J.D. Esko, Heparan sulfate regulates VEGF165- and VEGF121-mediated vascular hyperpermeability, J. Biol. Chem. 286 (2011) 737-745.

[10] J. Warford, C.D. Doucette, D.W. Hoskin, A.S. Easton, Murine T cell activation is regulated by surfen (bis-2-methyl-4-amino-quinolyl-6-carbamide), Biochem. Biophys. Res. Commun. 443 (2014) 524-530.

[11] G. Pescitelli, L. Di Bari, N. Berova, Conformational aspects in the studies of organic compounds by electronic circular dichroism, Chem. Soc. Rev. 40 (2011) 4603-4625.

[12] R.V. Person, B.R. Peterson, D.A. Lightner, Bilirubin conformational analysis and circular dichroism, J. Am. Chem. Soc. 116 (1994) 42-59.

[13] C.C. Bott, T. Kurucsev, Determination of transition moment directions by means of dichroic spectra in stretched polymer films: Part 1. - Orientation of solutes, J. Chem. Soc., Faraday Trans. 71 (1975) 749-755.

[14] A. Albert, R. Goldacre, J. Phillips, The strength of heterocyclic bases, J. Chem. Soc. (1948) 2240-2249.

[15] M. Schuksz, Small molecule interactions with heparan sulfate, Ph.D. Thesis, University of California, San Diego, Ann Arbor, 2009, pp. 208.

[16] L. Elson-Schwab, Selectivity in the interactions between positively charged small molecules and negatively charged biopolymers, Ph.D. Thesis, University of California, San Diego, Ann Arbor, 2006, pp. 236-236 p.

[17] A. Ziegler, J. Seelig, Binding and clustering of glycosaminoglycans: a common property of mono- and multivalent cell-penetrating compounds, Biophys. J. 94 (2008) 21422149. 
[18] L. Zhang, N. Li, F. Zhao, K. Li, Spectroscopic study on the interaction between methylene blue and chondroitin 4-sulfate and its analytical application, Anal. Sci. 20 (2004) 445-450. 
<smiles>Cc1cc(N)c2cc(NC(=O)Nc3ccc4nc(C)cc(N)c4c3)ccc2n1</smiles><smiles></smiles>

\section{Scheme 1}

Linear and crescent-shaped planar structures of surfen. The crescent-shaped form represents the structure found in the cocrystal complex of anthrax lethal factor (PDB id. 1PWP). Dotted line shows the nitrogen-nitrogen interatomic distance. 


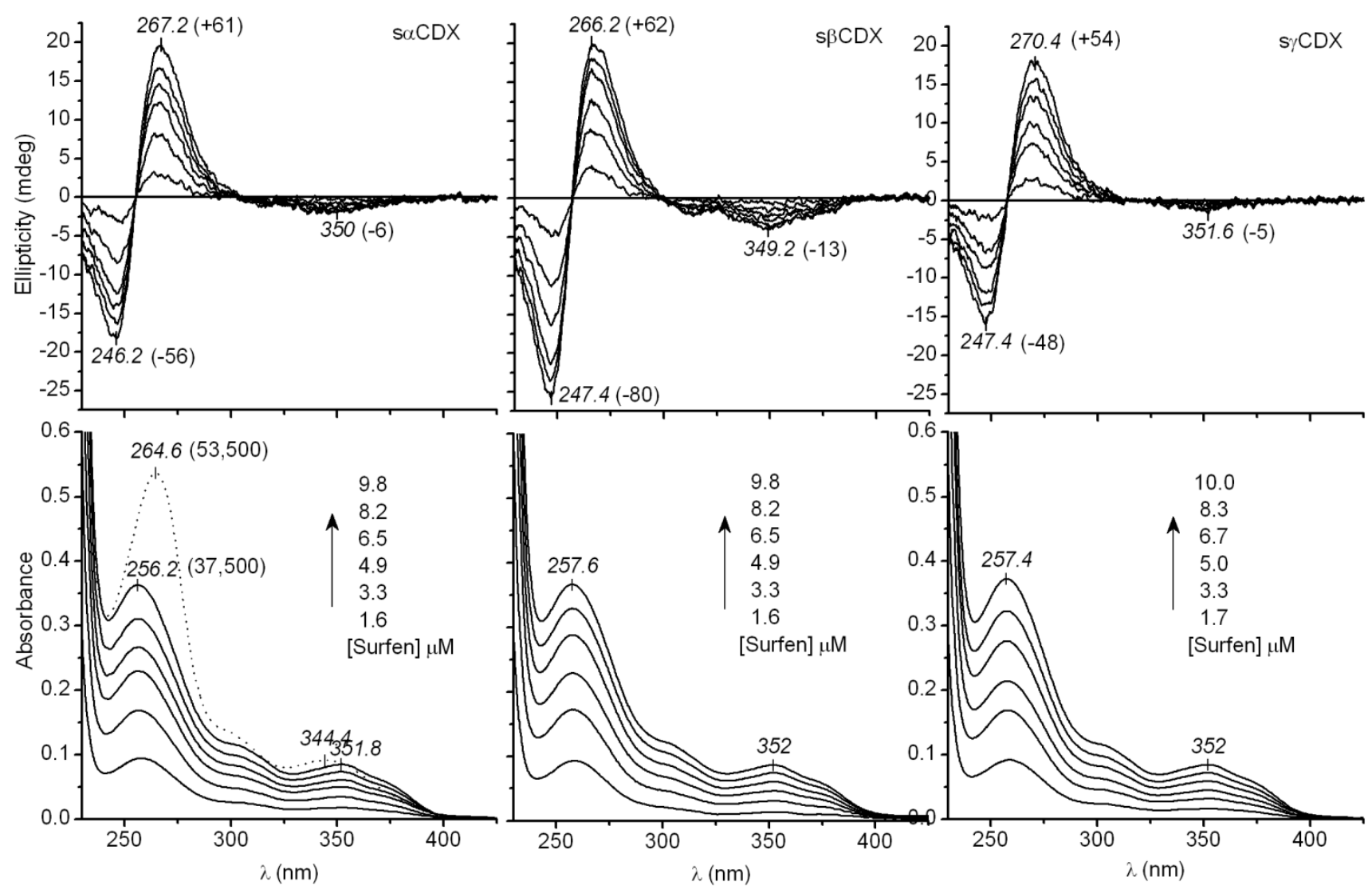

\section{Figure 1}

Induced CD and UV absorption spectra of surfen added into $3 \mu \mathrm{M}$ solution of sulfated $\alpha-, \beta-$, and $\gamma$-CDX (50 mM Tris-HCl buffer $\mathrm{pH}$ 7.4, $\left.100 \mathrm{mM} \mathrm{NaCl}, 25^{\circ} \mathrm{C}\right)$. Molar absorption $(\varepsilon)$ and dichroic absorption cofficients $(\Delta \varepsilon)$ calculated by using the total molar concentration of surfen in the sample solutions are shown in parentheses. Dotted line (left panel): UV spectrum of 10 $\mu \mathrm{M}$ surfen recorded in CDX-free buffer solution. 


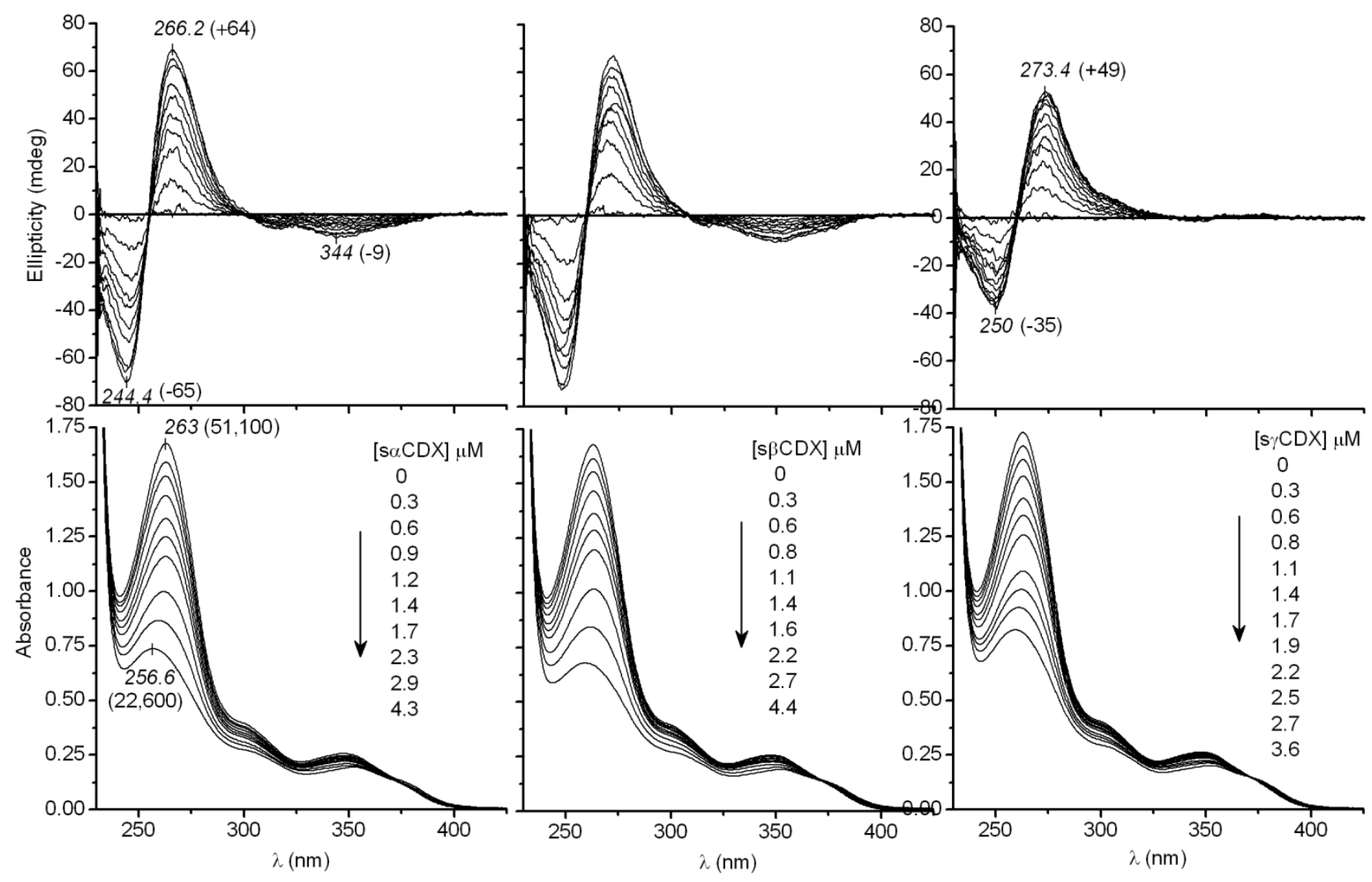

Figure 2

Induced CD and UV absorption spectra of $32 \mu \mathrm{M}$ surfen titrated with sulfated $\alpha-, \beta-$, and $\gamma-$ CDX (50 mM Tris- $\mathrm{HCl}$ buffer $\left.\mathrm{pH} 7.4,100 \mathrm{mM} \mathrm{NaCl}, 25^{\circ} \mathrm{C}\right)$. Molar absorption $(\varepsilon)$ and dichroic absorption cofficients $(\Delta \varepsilon)$ calculated by using the total molar concentration of surfen in the sample solutions are shown in parentheses. 


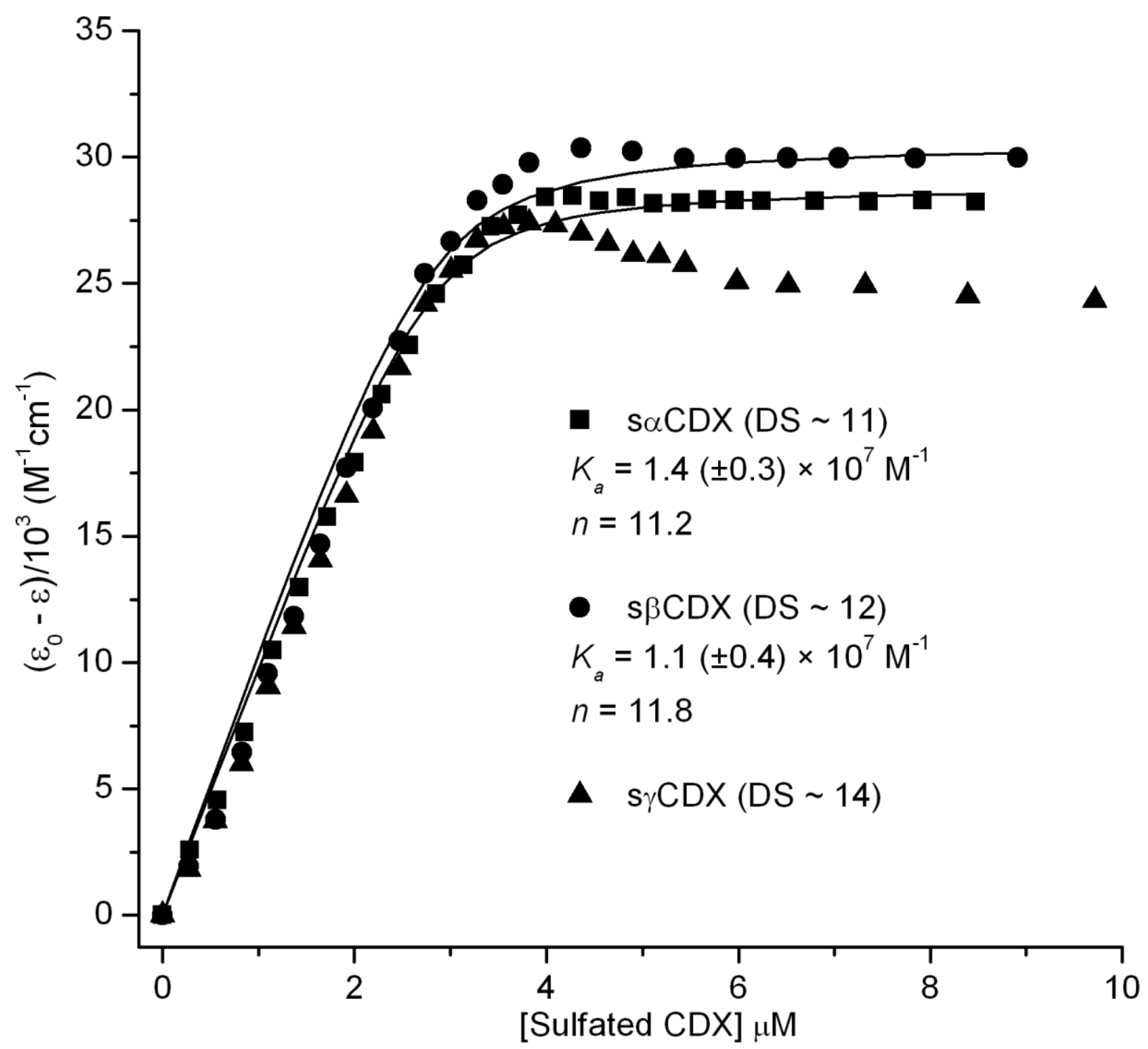

Figure 3

UV absorption changes plotted against the sulfated CDX concentration of the sample solution containing $32 \mu \mathrm{M}$ surfen. $\varepsilon_{0}$ : molar absorption coefficient of the main UV peak of surfen measured in CDX-free buffer solution. $\varepsilon$ : molar absorption coefficient of surfen measured with added CDX. Solid lines are the results of non-linear curve fiting analysis. Estimated association constants $\left(K_{\mathrm{a}}\right)$ and the number of surfen binding sites $(n)$ per a CDX molecule are shown. 
Electronic Supplementary Material (online publication only)
Click here to download Electronic Supplementary Material (c

Click here to download Electronic Supplementary Material (online publication only): Supplementary Data.docx 
Conflict of Interest

Click here to download Conflict of Interest: coi_disclosure.pdf 